\title{
Sensorless Control of Commutation Winding Low-Power Brushless DC Motor Based on the Use of Back-EMF
}

\author{
V. Enin ${ }^{1}$, A. Stepanov ${ }^{2}$ \\ Chair "Electrical engineering and industrial electronical”, Bauman Moscow State Technical University, \\ Moscow, Russian Federation \\ E-mail: ${ }^{1}$ enin@bmstu.ru, ${ }^{2}$ stepanov.bmstu@gmail.com
}

Received: June 10, 2019

\begin{abstract}
The method of sensorless control of switching of windings of three-section BLDC motor with permanent magnets based on calculation of back-EMF of rotation is proposed. After converting the equations of the three-section BLDC motor to a two-phase system, the switching moments of the windings are determined. Switching moments are calculated using a function representing the ratio of back-EMF rotations computed for a two-phase system. In these moments back-EMF of the turned off and turned on sections are equal. Using this function, signals are generated to control the transistors of inverter. We consider a BLDC motor with a trapezoidal back-EMF of rotation, which is approximated by a piecewise linear function and an inscribed ellipse. Modeling of three-section BLDC using the proposed method of sensorless control of switching windings confirmed the effectiveness of the method and the possibility of its use in a wide range of rotor speeds.
\end{abstract}

Keywords: brushless DC motor, sensorless control, back-EMF, approximation, simulation.

\section{INTRODUCTION}

In a number of areas of technology and industry: instrumentation, control systems and navigation of aircrafts, because of its compactness, reliability and low prices, sensorless electrical drive, in particular to brushless DC motors, find incrasing use. The works [1-7] are devoted to design and control of the electric drive systems with brushless motors. The widespread use of BLDC in the industry is associated with the development of power electronics and semiconductor technologies, which led to the creation of a new element base of intelligent integrated circuits. Such integrated circuits contain not only power electronic components (diodes, transistors), but also power element control devices - drivers. The keys are traditionally controlled by signals from the rotor position sensor (SPR). The use of the rotor position sensor complicates the design of the motor, increases the price and reduces its reliability, since the operation of the sensor is influenced by external environmental conditions: temperature, humidity, vibration, smoke, radiation. The other approach is based on intensively investigated in recent time methods of sensorless control of commutation of the BLDC motors. Most of the research on the development of sensorless control of switching windings of BLDC motors

(C) V. Enin, A. Stepanov, 2019 
is based on the calculation of the back-EMF of rotation or flux coupling of the motor windings, which are calculated by switching signals for the inverter. When using back-EMF, which is calculated from the voltage at the terminals of the electric motor and the current in the motor windings, the rotor position is determined by the intersection of zero back-EMF rotation [8]. Switching is performed after passing the back-EMF rotation through zero. The error of determining the moment of switching of the sections of the plug can result in unreliable operation, especially at high speeds of rotation of the rotor. In this regard, a number of works are devoted to the development of methods for correcting the error of switching moments of motor sections. In [8] the method of back-EMF rotation is developed for non-ideal back-EMF and an adaptive method of compensation of switching errors based on the analysis of backEMF at the time of switching on and off the section. Paper [9] proposed a method for improving the accuracy of the switching points using the method of least squares. Sensorless control for brushless DC monor based on the line-to-line back-EMF is proposed in paper [10]. In works [11-12] methods of compensation of an error of determination of the moments of switching of windings taking into account not ideality of back-EMF of rotation are offered. Methods based on the analysis of the back-EMF of rotation have the disadvantage, namely, the back-EMF of rotation depends on speed of rotation of the rotor, which complicates the determination of the moments of switching in a wide range of speeds of rotation of the rotor. In [13-16], a function (called the G-function) is used to determine the commutation point, which is the ratio of the back-EMF of the sections calculated from the current and voltage of the sections. The commutation points are calculated on the basis this function. Impulses are formed, when denominator of the G-function takes the value of zero heresy. The resulting signal contains noise and a high-frequency component generated by the operation of diodes, which is eliminated by the low-frequency filter. The disadvantage of sensorless control methods based on the calculation of back-EMF is the problem of calculation of switching signals at low speed and at a stationary rotor. The strategy of sensorless control at start-up of BLDC at perturbation by loading is proposed in paper [17].

Method improved sensorless control based on a simple compensation algorithm using zero-crossing point signals is proposed in [18]. In paper [19], the analysis of the third harmonic of the back-EMF is used for determining the position of the rotor.

In [20] a method of sensorless control of a two-section brushless DC motor (BLDC) was developed, based on the analysis of a function that does not depend on the speed of rotation and forms pulses at the equality of the back-EMF of rotation of the first and second sections. These pulses are used for switching sections. Despite the large number of works on sensorless control, the problem of reliability and accuracy of determining the switching points, as well as the problem of starting the engine are relevant and require further research.

This paper proposes a method for sensorless switching control of windings of a threesection brushless DC motor. The case of 120 degree switching and connection of windings by a star with an isolated common point is considered. Calculation of switching points is made by converting the equations of electrical equilibrium to a fixed coordinate system $\alpha, \beta$.

\section{Mathematical Model of Three-Section Brushless DC Electric Motor}

The power supply circuit of the windings of a three-section DC brushless motor by an electronic switch on field-effect transistors [1] is shown in Fig. 1. The equations in phase coordinates for the BLDC sections with permanent magnets taking into account of the sections have the form (the case of nonsalient rotor is considered): 


$$
\begin{aligned}
& R i_{\mathrm{a}}+L \frac{d i_{\mathrm{a}}}{d t}+e_{\mathrm{a}}(t)=u_{\mathrm{an}}(t), \\
& R i_{\mathrm{b}}+L \frac{d i_{\mathrm{b}}}{d t}+e_{\mathrm{b}}(t)=u_{\mathrm{bn}}(t), \\
& R i_{\mathrm{c}}+L \frac{d i_{\mathrm{c}}}{d t}+e_{\mathrm{c}}(t)=u_{\mathrm{cn}}(t),
\end{aligned}
$$

where $R$ is the active resistance of the winding section of the stator; $L$ is inductance of winding section; $u_{\mathrm{an}}, u_{\mathrm{bn}}, u_{\mathrm{cn}}$ are phase voltage on the windings; $i_{\mathrm{a}}, i_{\mathrm{b}}, i_{\mathrm{c}}$ are currents in the windings of the stator sections; $e_{\mathrm{a}}, e_{\mathrm{b}}, e_{\mathrm{c}}-$ back-EMF of the windings of the stator.

When connecting with a star without a neutral line $i_{\mathrm{a}}+i_{\mathrm{b}}+i_{\mathrm{c}}=0$. Voltage of winding, if neutral line has not been extracted, is calculated with a use of virtual neutral line. For function back-EMF approximated by the sinusoidal function $e_{\mathrm{a}}+e_{\mathrm{b}}+e_{\mathrm{c}} \approx 0$ is also assumed. Then voltage of winding are equal to

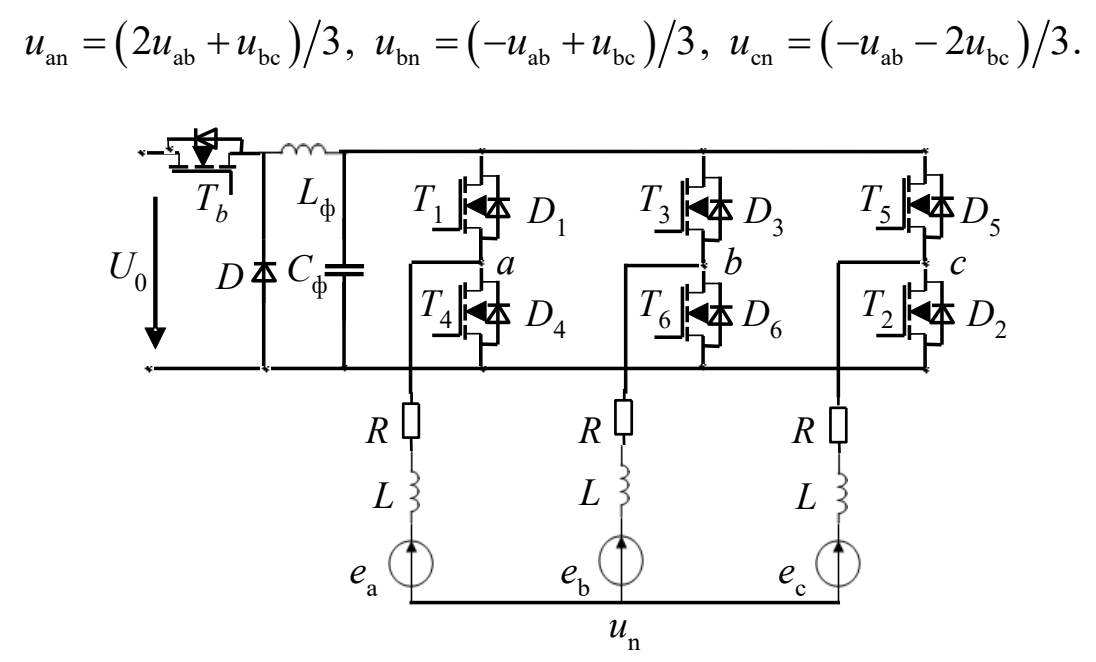

Figure 1. Brushless DC motor drive system

Let us pass from the equations in phase coordinates (1)-(3) to the mathematical model of the machine in a fixed coordinate system $\alpha, \beta$ on the basis of the transformation

$$
\begin{gathered}
u_{\alpha}=\frac{2}{\sqrt{6}} u_{\mathrm{a}}-\frac{1}{\sqrt{6}} u_{\mathrm{b}}-\frac{1}{\sqrt{6}} u_{\mathrm{c}}, \\
u_{\beta}=\frac{1}{\sqrt{2}} u_{\mathrm{b}}-\frac{1}{\sqrt{2}} u_{\mathrm{c}} .
\end{gathered}
$$

The inverse transition from the coordinates of the state in a fixed coordinate system to phase voltages or currents is based on the inverse transformation

$$
\begin{gathered}
u_{a}=\frac{2}{\sqrt{6}} u_{\alpha}, \\
u_{\mathrm{b}}=-\frac{1}{\sqrt{6}} u_{\alpha}+\frac{1}{\sqrt{2}} u_{\beta}, \\
u_{\mathrm{c}}=-\frac{1}{\sqrt{6}} u_{\alpha}-\frac{1}{\sqrt{2}} u_{\beta} .
\end{gathered}
$$


Transforming the system (1)-(3) with use of (4)-(8), we obtain

$$
\begin{aligned}
& R i_{\alpha}+L \frac{d i_{\alpha}}{d t}+e_{\alpha}(t)=u_{\alpha}, \\
& R i_{\beta}+L \frac{d i_{\beta}}{d t}+e_{\beta}(t)=u_{\beta},
\end{aligned}
$$

where $e_{\alpha}(t), e_{\beta}(t)$ are back-EMF sections in the system $\alpha, \beta$.

Calculate the back-EMF $e_{\alpha}(t), e_{\beta}(t)$ can be as follows

$$
\begin{aligned}
& e_{\mathrm{ab}}(t)=u_{\mathrm{a}}-u_{\mathrm{b}}-R\left(i_{\mathrm{a}}-i_{\mathrm{b}}\right)-L\left(\frac{d i_{\mathrm{a}}}{d t}-\frac{d i_{\mathrm{b}}}{d t}\right), \\
& e_{\mathrm{bc}}(t)=u_{\mathrm{b}}-u_{\mathrm{c}}-R\left(i_{\mathrm{b}}-i_{\mathrm{c}}\right)-L\left(\frac{d i_{\mathrm{b}}}{d t}-\frac{d i_{\mathrm{c}}}{d t}\right), \\
& e_{\mathrm{ca}}(t)=u_{\mathrm{c}}-u_{\mathrm{a}}-R\left(i_{\mathrm{c}}-i_{\mathrm{a}}\right)-L\left(\frac{d i_{\mathrm{c}}}{d t}-\frac{d i_{\mathrm{a}}}{d t}\right),
\end{aligned}
$$

then

$$
\begin{gathered}
e_{\alpha}(t)=\frac{1}{\sqrt{6}}\left(e_{\mathrm{ab}}(t)-e_{\mathrm{ca}}(t)\right), \\
e_{\beta}(t)=\frac{1}{\sqrt{2}}\left(e_{\mathrm{bc}}(t)\right) .
\end{gathered}
$$

Electromagnetic torque in the stationary coordinate system $\alpha, \beta$, equal to

$$
T=\frac{e_{\alpha} i_{\alpha}+e_{\beta} i_{\beta}}{\omega_{m}}
$$

where $\omega_{\mathrm{m}}$ is the angular velocity of the rotor.

Next, we consider the 120 degree switching sections of the rotor windings, in which two sections operate simultaneously, and one of the sections is disconnected from the source.

Trapezoidal function $\Phi^{\prime}=\mathrm{d} \Phi / \mathrm{d} \theta\left(\Phi\right.$ is magnetic flux, $\theta=p \omega_{\mathrm{m}}$ electric angle, $\omega_{\mathrm{m}}$ is rotor rotation angle, $p$ is number pair pole) is approximated by piecewise linear function with inscribed ellipse Fig. 2. The approximating function is a continuous function with a continuous derivative, which is its advantage in the simulation and calculation of the back-EMF rotation. The ellipse is described by the equation

$$
\frac{\theta^{2}}{a^{2}}+\frac{\left(\Phi^{\prime}-\Phi_{\mathrm{c}}^{\prime}\right)^{2}}{b^{2}}=1,
$$

where $a, b$ are the large and small axis of the ellips

$$
\Phi^{\prime}{ }_{\mathrm{b}}=\Phi^{\prime}{ }_{\text {max }}-h \text {. }
$$

For Fig. 2 denoted by $\theta_{\mathrm{p}}$ the period of trapezoidal, function. On the intervals $\left[-\theta_{\mathrm{p}} / 4, \theta_{1}\right]$, $\left[\theta_{2}, \theta_{\mathrm{p}} / 4\right]$ the dependence is approximated by a linear function, on the interval $\left[\theta_{1}, \theta_{2}\right]$ the dependence is approximated with an ellipse. Given: $\Phi_{\max }^{\prime}-$ maximum value, $\Phi_{\mathrm{b}}^{\prime}$ - value at the boundary of the interval of the function $\Phi^{\prime}(\theta)$. The angle of inclination of the line at intervals $\left[-\theta_{\mathrm{p}} / 4, \theta_{1}\right],\left[\theta_{2}, \theta_{\mathrm{p}} / 4\right]$ is determined by the formula $v= \pm\left(\Phi_{\mathrm{b}}^{\prime}\right) / \theta_{1}$. 


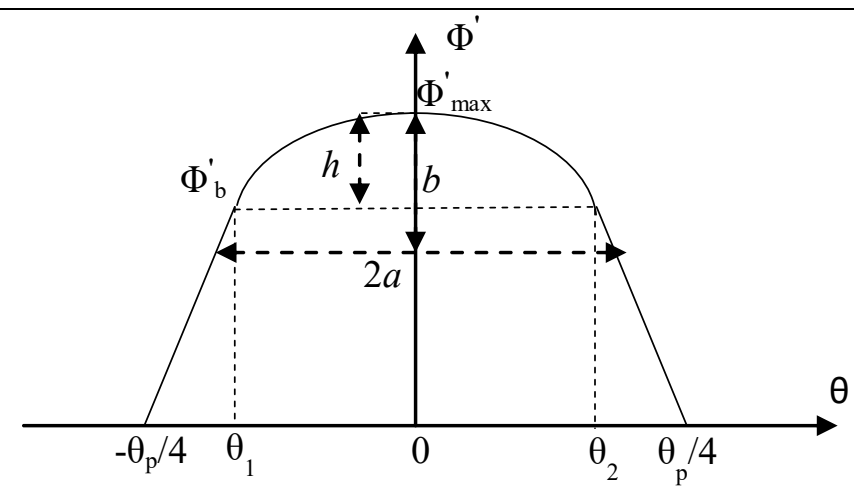

Figure 2. Approximation of the dependence of the back-EMF on the angle of rotation of the rotor

At the point $\theta_{1}$, the line is tangent to the ellipse, then it must hold

$$
v=-\frac{\theta_{1} b^{2}}{a^{2}(b-h)} .
$$

It must also hold

$$
(b-h)^{2}=b^{2}\left(1-\frac{\theta_{1}^{2}}{a^{2}}\right) .
$$

Then parameters $a, b$ will be equal to

$$
\begin{gathered}
b=d 1 / d 2, \\
d_{1}=h^{2}+v h \theta_{1}, \quad d_{2}=v \theta_{1}+2 h, \\
a=\sqrt{\frac{h_{1}}{h_{2}}}, \\
h_{1}=\theta_{1} b^{2}, \quad h_{2}=v(b-h) .
\end{gathered}
$$

Setting the angle $\theta$ function $\Phi^{\prime}(\theta)$ on the interval $\left[\theta_{1}, \theta_{2}\right]$ is calculated by the formula

$$
\Phi^{\prime}(\theta)=\Phi_{\text {max }}^{\prime}-b+\sqrt{b^{2}\left(1-\theta^{2} / a^{2}\right)},
$$

The dependence of the back-EMF sections in relative units expressed using the function $\Phi^{\prime}(\theta)$ is shown in Fig. 3.

The chosen approximation of the function $\Phi^{\prime}(\theta)$ is essentially a spline function. On the intervals $\left[-\theta_{\mathrm{p}} / 4, \theta_{1}\right]$ and $\left[\theta_{2}, \theta_{\mathrm{p}} / 4\right]$ this function $\Phi^{\prime}(\theta)$ is a linear function of the electrical angle, and the interval $\left[\theta_{1}, \theta_{2}\right]$ is a nonlinear function of the angle $\theta$. An inscribed ellipse determines the nonlinear function, the parameters are calculated by formulas $(9)-(11)$. The choice of parameters $\Phi_{\mathrm{b}}^{\prime}, \Phi_{\max }^{\prime}, \theta_{\mathrm{p}}, \theta_{1}, \theta_{2}$ affects the value of the switching interval and the switching moments of the windings in which the back-EMF of the switched-off and switched-on phase coincides.

The value $h=\Phi_{\text {max }}^{\prime}-\Phi_{\mathrm{b}}^{\prime}, \theta \in\left[\theta_{1}, \theta_{2}\right]$ determines how much the amplitude of the phase back-EMF differs from the constant. Also, the choice of these parameters can improve the accuracy of the approximation of the magnetic flux and, accordingly, the function $\Phi^{\prime}(\theta)$ from the electric angle $\theta$. The most widespread in practice is $120^{\circ}$ degree switching, in which the winding is connected to the source at an interval of $120^{\circ}$ electric degrees, then disconnected 
from the source at an interval of $60^{\circ}$ electric degrees. The proposed method of approximation will more accurately describe for different types of BLDC the dependence of the back-EMF on the electric angle $\theta$ and thus increase the accuracy of determining the switching points.
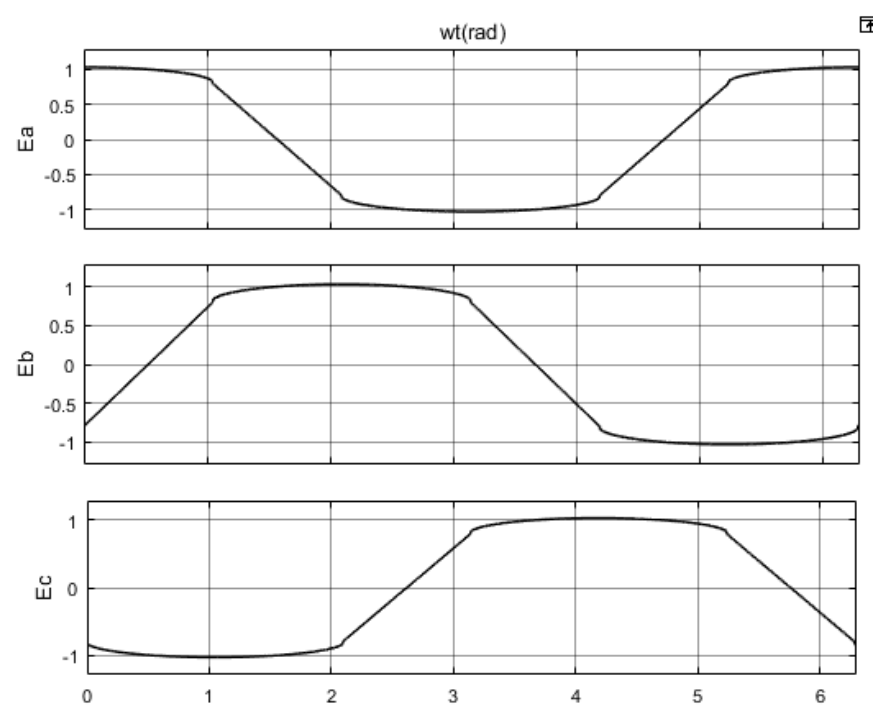

Figure 3. The system is three-phase back-EMF

\section{SENSORLESS COMMUNiCATION SECTIONS OF THE BLDC Motor IN THE TwO PHASE COORDINATES}

Now we consider on 120-degree commutation. The section connected to the source will be called active and back-EMF denoted $e_{\mathrm{w}}(t)$. For section disable, back-EMF is denoted by $e_{\text {on }}(t)$. The back-EMF of the section to be switched on at the next switching, is denoted $e_{\text {off }}(t)$.

Then, the transition to a fixed coordinate system $\alpha, \beta$, can be made as follows

$$
\begin{gathered}
e_{\alpha}(t)=\frac{2}{\sqrt{6}} e_{\mathrm{w}}(t)-\frac{1}{\sqrt{6}} e_{\mathrm{on}}(t)-\frac{1}{\sqrt{6}} e_{\mathrm{off}}(t), \\
e_{\beta}(t)=\frac{1}{\sqrt{2}} e_{\mathrm{on}}(t)-\frac{1}{\sqrt{2}} e_{\mathrm{off}}(t) .
\end{gathered}
$$

When switching sections of the stator windings taking into account (12), (13) we will use a function that represents the ratio of the back-EMF sections of the stator in a fixed coordinate system $\alpha, \beta$

$$
H(t)=\frac{e_{\alpha}(t)}{e_{\beta}(t)} .
$$

At the time of switching the back-EMF of the switched section must be equal to the backEMF of the switched section, at this point the function $H(t)(14)$ takes an infinite value. Then, by setting some threshold value $H_{\mathrm{t}}$, switching will be performed when the modulo function $H(t)$ exceeds the threshold value. Then the included section with the back-EMF $e_{\mathrm{on}}(t)$ is disconnected from the source, and the section disconnected with the back-EMF $e_{\text {off }}(t)$ is connected to the output of the voltage source. The next miscomputation the interval is accepted. The pulses generated by the function (14) determine switching moments. 
Back-EMF $e_{\alpha}(t), e_{\beta}(t)$ contains high-frequency noise generated by PWM, pulses during operation of the inverter keys, which can lead to the erroneous determination of synchronization points. Using a low-pass filter reduces the impact of these factors. The accuracy of the switching moment also depends on the value of the threshold $H_{\mathrm{t}}$ and rotor speed $\omega_{\mathrm{m}}$, sampling rate $\Delta t_{\mathrm{d}}$. Increasing the threshold $H_{\mathrm{t}}$ for the formation of the switching signal of the sections increases the accuracy of determining the switching moment, but if the threshold is too large and the rotor speed is high, it can lead to the omission of the synchronization point and disruption of the stable operation of the motor. The calculation of switching moments has the advantage because the ratio of the backi-EMF does not depend on the rotor speed and can be used in a wide range of speeds.

\section{SIMULATION AND EXPERIMENT}

To substantiate and study the effectiveness of the proposed algorithm of sensorless control of the valve motor, a simulation of a contactless low-power electric motor of the DLBC type is carried out. The motor is an electric machine with a three-section winding on the stator and a multi-pole rotor with permanent magnets. The number of pairs of poles is 4 . The active resistance and inductance of the stator sections are respectively $R=6.0 \mathrm{Ohms}, L=0.00042 \mathrm{H}$. The supply voltage of a constant source is $27 \mathrm{~V}$. The sections of the stator windings are connected into a star. The functional scheme of sensorless switching control of the three-section winding is shown in Fig. 4.

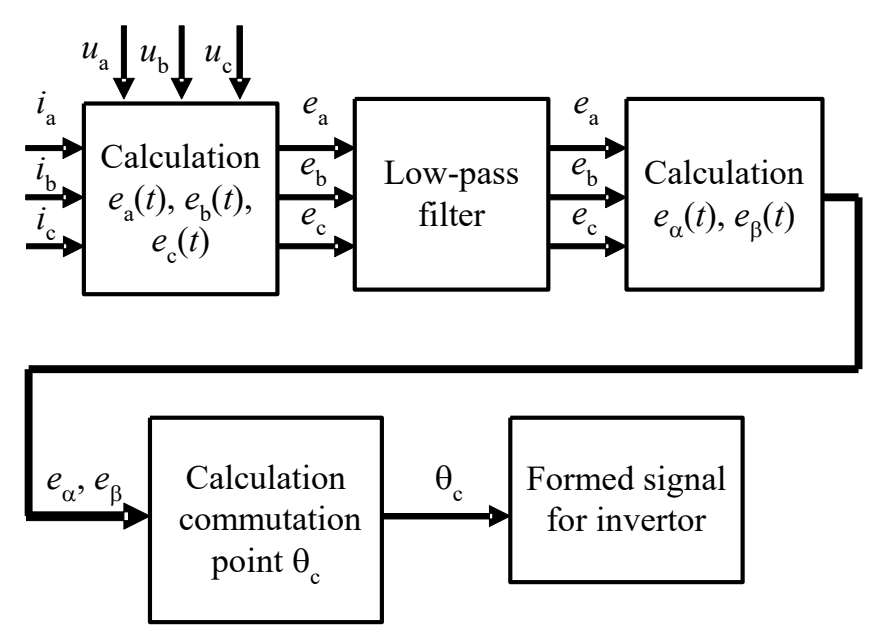

Figure 4. The block diagram for the switching control of the windings BLDC

When the rotor rotates, back-EMF is induced in the stator windings. The back-EMF is calculated from the voltages $u_{\mathrm{a}}, u_{\mathrm{b}}, u_{\mathrm{c}}$, supplied to the section and section currents $i_{\mathrm{a}}, i_{\mathrm{b}}, i_{\mathrm{c}}$. Switching of windings is made at equality of back-EMF of rotation of the switched-off and switched-on phase, (120 degree switching is considered). In case of dependence of the backEMF on time, calculated from the phase voltages and current sections, as a result of the operation of the keys of the power semiconductor invertor pulses occur.

After calculating the back-EMF, these pulses are smoothed by a low-pass filter. By phase back-EMF $e_{\mathrm{a}}(t), e_{\mathrm{b}}(t), e_{\mathrm{c}}(t)$ are calculated back-EMF in a fixed coordinate system $e_{\alpha}(t), e_{\beta}(t)$. Back-EMF in a fixed coordinate system are used to determine the switching moments of the windings.

The start-up of BLDC with the subsequent transition to sensorless control of switching of windings was investigated. A direct start of the motor under load was made when switching 
signals were supplied in the form of a periodic sequence of rectangular pulses. The pulse period was selected according to the motor parameters. The transition to sensorless control is possible by increasing the motor speed to a value at which the counter-EMF can be isolated from the noisy signal. The time of transition after start-up to sensorless control was set.

Fig. 5 shows the rotation speed, torque and rotation angle of the rotor, the transition to sensorless control was made at $t=0.01 \mathrm{~s}$, while the speed after the start increased by $\approx 100 \mathrm{rpm}$. Fig. 6 shows phase currents.

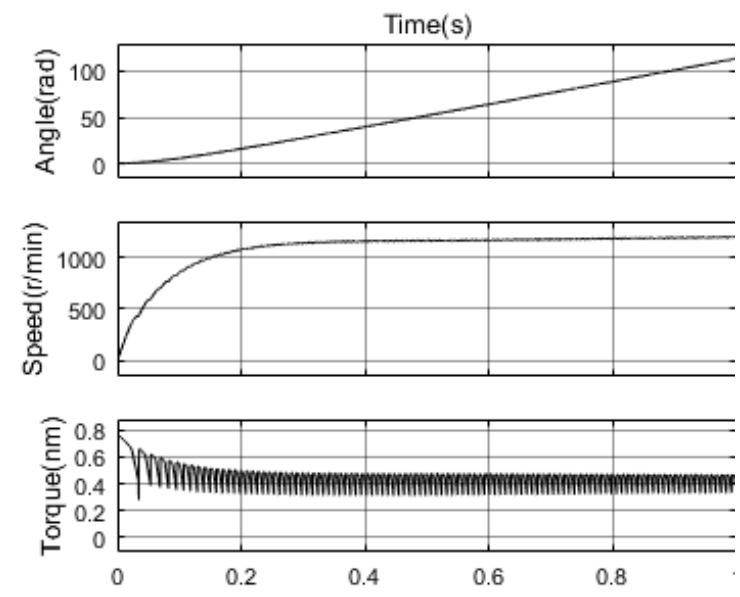

Figure 5. Start and transition to sensorless control
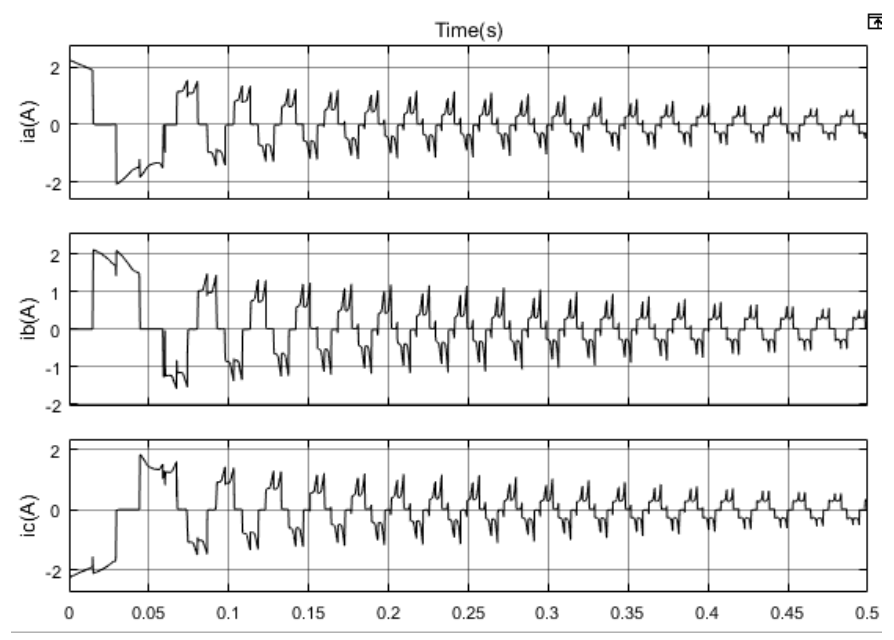

Figure 6. Phase currents in motor windings at start-up and transition to sensorless control

\section{CONCLUSION}

This paper proposed a new algorithm for sensorless determination of switching angles three-section brushless DC permanent magnet motor and control power semiconductor invertor. The sensorless control algorithm is based on the transformation of the three-section motor equations to a two-phase system in a fixed coordinate system $\alpha, \beta$.

Communication points are determined by a use calculating the back-EMF rotation in a fixed system $\alpha, \beta$. The back-EMF are described trapezoidal functions which consists of the piecewise linear functions and the inscribed ellipse. The start-up problem is solved by direct starting of the motor and transition to sensorless control after some delay equal to several periods. 
The advantage of the proposed algorithm is the independence of the ratio of the backEMF sections of the rotor speed, which allows the use of the proposed method in a wide range of speeds.

\section{REFERENCES}

1. Arakelyan, A.K., \& Afanas'ev, A.A. (2006). Ventil'nyye elektricheskiye mashiny $\mathrm{v}$ sistemakh reguliruyemogo elektroprivoda [The rectifier of the electric machine in the systems of electric drive]. In 2 volumes. Moscow : Higher school. (In Russian).

2. Tsatsenkin, V. K. (1991). Bezreduktornyy avtomatizirovannyy elektroprivod s ventil'nymi dvigatelyami [Direct drive automated electric drive with brushless DC motors]. Moscow : MPEI. (In Russian).

3. Belkovsky, A. P., \& Tsatsenkin, V. K. (2010). Pretsizionnyy elektroprivod s ventil'nymi dvigatelyami [Precision electric drive with brushless DC motors]. Moscow : MPEI. (In Russian).

4. Zimin, E. N., Katsevich, V. L., \& Kozyrev, S. K. (1981). Elektroprivody postoyannogo toka s ventil'nymi preobrazovatelyami [DC electric drives with power converters]. Moscow : Energoizdat. (In Russian).

5. Baranov, M. V., Brodovskiy, V. N., Zimin, A. V., Karzanov, B. N. (2006). Elektricheskiye sledyashchiye privody s momentnym upravleniyem ispolnitel'nymi dvigatelyami [Electric servo actuators with torque in the controlled engines]. Moscow : Bauman Moscow State Technical University. (In Russian).

6. Soloviev, V.A. (2004). Nepreryvnoye tokovoye upravleniye ventil'nymi dvigatelyami [Continuous current control of electric drive]. Moscow : Kosygin MSTU. (In Russian).

7. Ovchinnikov, E., \& Lebedev, N. A. (1979). Beskontaktnyye dvigateli postoyannogo toka [Brushless DC motors]. Leningrad : Nauka. (In Russian).

8. Halvaei Niasar, A., Vahedi, A., \& Moghbelli, H. (2008). A novel position sensorless control of a fourswitch, brushless DC motor drive without phase shifter. IEEE Transactions on Power Electronics, 23, 3079-3087. doi: 10.1109/tpel.2008.2002084.

9. Guo, R. C., Mu, Z., \& Li, J. D. (2017). Research on position sensorless control system of high-speed brushless DC motor. In: 9th International Conference on Intelligent Human-Machine Systems and Cybernetics, 2017 (pp. 62-65). IEEE. doi: 10.1109/IHMSC.2017.21.

10. Liu, G., Cui, C., Wang, K., Han, B., \& Zheng, S. (2016). Sensorless control for high-speed brushless DC motor based on the line-to-line back EMF. IEEE Transactions on Power Electronics, 31, 4669-4683. doi: 10.1109/TPEL.2014.2328655.

11. Li, H., Zheng, S., \& Ren, H. (2017). Self-correction of commutation point for high-speed sensorless BLDC motor with low inductance and nonideal back EMF. IEEE Transactions on Power Electronics, 32, 642651. doi: 10.1109/TPEL.2016.2524632.

12. Li, W., Fang, J., Li, H., \& Tang, J. (2016). Position sensorless control without phase shifter for high-speed BLDC motor with low inductance and nonideal back EMF. IEEE Transactions on Power Electronics, 31, 1354-1366. doi: 10.1109/TPEL.2015.2413593.

13. Su, G., McKeever, J. (2004). Low-cost sensorless control of brushless DC motor using a frequencyindependent phase shifter. IEEE Transaction on Power Electronics, 19, 296-302. doi: 10.1109/TPEL.2003.823174.

14. Chlandy, R., Kosh, C. (2008). Flatness-Based tracking of an electromagnetic VVT actuator with disturbance observer feedforward compensation. IEEE Transaction on Control System Technology, 16, 652-663. doi: 10.1109/TCST.2007.912121.

15. Chen, S., Zxou, X., Bai, G., Wang, K., Zhu, L. (2018). Adaptive commutation error compensation strategy based on a flux linkage function for sensorless brushless DC motor drives in a wide speed range. IEEE Transaction on Power Electronics, 33, 3752-3764. doi: 10.1109/TPEL.2017.2765355.

16. Chen, S., Liu, G., Zhu, L. (2017). Sensorless control strategy of a $315 \mathrm{~kW}$ high-speed BLDC motor based on a speed-independent flux linkage function. IEEE Transactions on Industrial Electronics, 64, 86078617. doi: 10.1109/TIE.2017.2698373. 
"Instrumentation Engineering, Electronics and Telecommunications - 2019"

Proceedings of the V International Forum (Izhevsk, Russia, November 20-22, 2019)

17. Liu, G., Chen, S., Zhen, S., Song, X. (2017). Sensorless low-current start-up strategy of 100-kW BLDC motor with small inductance. IEEE Transactions on Industrial Informatics, 13, 1131-1140. doi: 10.1109/TII.2016.2607158.

18. Park, J. S., Lee, K. L., Lee, S. G., Kim, W.H. (2019). Unbalanced ZCP compensation method for position sensorless BLDC motor. IEEE Transactions on Power Electronics, 34, 3020-3024. doi: 10.1109/TPEL.2018.2868828.

19. Song, X., Han, B., Zheng, S., Fang, J. (2018). High-precision sensorless drive for high-speed BLDC motors based on the virtual third harmonic back-EMF. IEEE transactions on Power Electronics, 33, 15281540. doi: 10.1109/TPEL.2017.2688478.

20. Enin, V. N., Stepanov, A. V. (2018). The commutation of BLDC motors in sensorless control via EMF of rotation. Herald of the Bauman Moscow State Technical University, 2018, 6(123), 87-101. doi: 10.18698/0236-3933-2018-6-87-101. (in Russian). 